\title{
Os Festejos como Estratégia de Fortalecimento Comunitário em Comunidade de Manaus (AM)
}

\author{
Kamila Bezerra de Araújo \\ Universidade Federal do Amazonas, AM, Brasil.
}

\author{
Marcelo Gustavo Aguilar Calegare \\ Universidade Federal do Amazonas, AM, Brasil.
}

Resumo: A comunidade Parque Riachuelo I, localizada em Manaus (AM), existe há 40 anos e foi fruto de ocupações desordenadas. Está sediada na zona urbana, mas ainda não é plenamente urbanizada, apresentando aspectos rurais (igarapés, mata virgem, ruas de barro). Por isso, sofre com a falta de infraestrutura, de acesso a serviços sociais básicos e de lazer. Apesar das dificuldades, os moradores organizam festejos em datas comemorativas. Assim, a partir de pesquisa de iniciação científica, neste artigo temos por objetivo apresentar quais festejos já aconteceram na comunidade e seu significado para os moradores, para examinar como os mesmos influenciaram no fortalecimento das redes comunitárias. Partindo da Psicologia Social Comunitária, realizamos pesquisa qualitativa, com seis entrevistas semiestruturadas com participantes-chave e respectiva análise de conteúdo. Os resultados apontam a lembrança de oito festejos marcantes, com o significado e importância de promover o engajamento e motivação nas lutas políticas, união, fortalecimento dos laços comunitários e sentimento de pertença. Verificamos que os festejos se tornaram uma ferramenta estratégica essencial para união e lazer, de modo que a cada festejo mais moradores participam e dialogam sobre as questões da comunidade, propiciando o fortalecimento comunitário.

Palavras-chave: Psicologia Comunitária, Festejos, Amazônia, Ambientes Rurais.

\section{The Festivities as a Strategy for Community Strengthening in a Manaus (AM) Community}

\begin{abstract}
The community Parque Riachuelo I, located in Manaus (AM), has existed for about 40 years and was the result of disordered occupations. It is based in the urban zone, but it is not yet fully urbanized, presenting rural aspects (small river, virgin forest, mud streets). Hence, it suffers from lack of infrastructure, access to basic social services and leisure. Despite the difficulties, the residents organize festivities on commemorative dates. From a scientific initiation research, in this paper we aim to present which festivities have already taken place in the community and their meaning for the residents, to examine how they influenced the strengthening of community network. From the point of view of Community Social Psychology, we conducted a qualitative research with six semi-structured interviews with key participants and performed a content analysis. The results pointed to the remembrance of eight outstanding festivities, with meaning and importance of engagement and motivation on political struggles, union, strengthening of community ties and belonging sense. We have verified that the festivities have become an essential strategy tool for union and leisure, so that in each celebration more residents participate and dialogue on community issues, promoting community strengthening.
\end{abstract}

Keywords: Community Psychology, Parties, Amazon, Rural Environments. 


\title{
Los Festejos como Estrategia de Fortalecimiento Comunitario en Comunidad de Manaus (AM)
}

\begin{abstract}
Resumen: La comunidad Parque Riachuelo I, ubicada en Manaus (AM), existe hace 40 años y fue fruto de ocupaciones desordenadas. Está ubicada en la zona urbana, pero aún no está totalmente urbanizada, presentando aspectos rurales (arroyos, selva virgen, calles de barro). Por eso, sufre con falta de infraestructura, de acceso a servicios sociales básicos y de ocio. A pesar de las dificultades, los residentes organizan festejos en fechas conmemorativas. Así, a partir de investigación de iniciación científica, en este artículo tenemos por objetivo presentar cuáles fiestas ya ocurrieron en la comunidad y su significado para los residentes, para examinar cómo los mismos influenciaron en el fortalecimiento de las redes comunitarias. Partiendo de la Psicología Social Comunitaria, realizamos investigación cualitativa, con seis entrevistas semiestructuradas con participantes clave y respectivo análisis de contenido. Los resultados apuntan el recuerdo de ocho fiestas más importantes, con el significado e importancia de promover el compromiso y motivación en las luchas políticas, unión, fortalecimiento de lazos comunitarios y sentimiento de pertenencia. Verificamos que las fiestas se han convertido en una herramienta estratégica esencial para la unión y el ocio, de modo que a cada festejo más residentes participan y dialogan sobre las cuestiones de la comunidad, propiciando el fortalecimiento comunitario.
\end{abstract}

Palabras clave: Psicología Comunitaria, Festejos, Amazonía, Ambiente Rural.

A cidade de Manaus, capital do Amazonas, situada na Região Norte do Brasil, teve seu crescimento urbano de forma desordenada e rápida, especialmente nos últimos 50 anos. De acordo com Pinto (2008), os períodos de extração da borracha (primeiro e segundo ciclo) e a implantação da Zona Franca de Manaus, no final da década de 1960, contribuíram fortemente para o grande período de desenvolvimento econômico, o qual trouxeram um crescimento populacional excessivo: migração de pessoas de outras cidades e, principalmente, da população rural do Amazonas em busca de emprego e qualidade de vida. Contudo, a falta de infraestrutura e de organização da cidade favoreceu as ocupações irregulares, o que configurou na intensa construção de moradias nas margens de igarapés, sem nenhuma estrutura ou rede de serviços básicos para os habitantes até o presente (Lobato, 2014).

Ainda segundo Pinto (2008), o Poder Público na década de 1980 passou a distribuir alguns loteamentos, devido à demasiada preocupação acerca do amplo desmatamento e da contaminação dos igarapés da cidade. Porém, tal iniciativa não foi o suficiente para conter a ocupação de áreas (ou "invasões", conforme ponto de vista), o crescimento desordenado e o impacto ambiental, que até os dias de hoje são visíveis nos bairros e comunidades periféricas da cidade de Manaus.
Dentre muitas comunidades levantadas nesse meio urbano desordenado, apresentamos a comunidade Parque Riachuelo I, situada na zona oeste de Manaus, no bairro Tarumã. O bairro é caracterizado por ocupações e loteamentos irregulares desde sua fundação (Pinto, 2008). Com cerca de 40 anos de existência, aproximadamente 600 habitantes e 150 famílias, a comunidade tem sua história marcada por lutas de posseiros e grileiros, que utilizavam métodos ilícitos para lotear e vender terrenos daquela área (Calegare, Ribeiro, Costa, Pires, \& Souza, 2015). A venda ilegal de terrenos sem infraestrutura influenciou diretamente no cenário atual da comunidade e na qualidade de vida dos habitantes, cujas condições básicas como saneamento, postos de saúde, sistemas de educação, linhas de ônibus, segurança e lazer, quando existentes, não são satisfatórias aos moradores. Portanto, apesar de ser uma comunidade sediada dentro da zona urbana de Manaus, ainda não é plenamente urbanizada, por apresentar aspectos rurais: igarapés, mata virgem e ruas de barro.

A comunidade apresenta habitantes com discrepantes condições socioeconômicas, de modo que identificamos uma distinção entre as moradias: algumas construções são amplas e com terrenos extensos (como se fossem sítios em uma zona rural), enquanto 
outras são de pequeno porte com terrenos menores, $o$ que indica um menor poder aquisitivo (típicas construções de periferia urbana). Essas diferenças sociais segregam os interesses: uns querem continuar com seus sítios e chácaras que lembram a vida rural; outros querem que o bairro seja urbanizado para que o ônibus circule lá dentro e possam ter acesso a outras benesses urbanas. Essa divergência entre os moradores tem influência direta na falta de envolvimento em questões políticas da comunidade que, apesar de possuírem uma liderança formal pela Associação de Moradores e Amigos do Parque Riachuelo I (AMAR), mostram um característico sentimento de desconfiança e abandono. Tais sentimentos são oriundos da falta de ações reivindicatórias organizadas pela AMAR e, principalmente, pelo descaso do Poder Público referente à falta de infraestrutura, de serviços básicos de saúde, de transporte e de lazer na comunidade (Calegare et al., 2015).

Apesar do descontentamento geral e sentimento de abandono dos moradores, já ocorreu, tanto por líderes informais quanto pela AMAR, reivindicações por asfaltamento, implantação de um posto de saúde, bem como a organização de festejos em datas comemorativas na comunidade, embora não exista um espaço físico para suas realizações, como praças ou áreas para prática de esportes. Desse modo, a realização desses festejos despertou nosso interesse por se mostrar como opção de lazer e de expressão de manifestações culturais da comunidade, apesar das dificuldades apresentadas.

No Amazonas, há diversas manifestações culturais características, tais como o boi-bumbá e a ciranda. Ambos fazem parte da cultura amazônica e trazem questões sobre o meio ambiente e o misticismo, pautados nos saberes indígenas, caboclos e ribeirinhos, de modo que tais manifestações conferem um sentimento de valorização dos rios e florestas (Nogueira, 2008). Na comunidade Parque Riachuelo I, há comemorações de datas festivas, como as festas juninas, onde os moradores introduzem as manifestações socioculturais amazônicas com o boi-bumbá de Parintins, visto que alguns deles são oriundos desse município. Nesse momento, são realizadas apresentações artísticas e são elucidados temas a respeito da história do boi e do meio ambiente que, de modo indireto, evocam as questões enfrentadas pelos moradores na comunidade acerca do ambiente que ocupam.

De acordo com Castro (2012), os festejos populares são manifestações culturais provenientes de eventos sociais, religiosos, econômicos ou políticos que constituem elementos importantes a respeito da transição de papéis sociais e ruptura do cotidiano urbano. Nessa perspectiva, o festejo quebra a rotina e permite a ludicidade como uma válvula de escape para a população, sendo realizada dentro de uma temática de datas comemorativas.

Contudo, ao associarmos os conteúdos abordados nos festejos amazônicos e as dificuldades enfrentadas diariamente pelos moradores, questionamos sobre os festejos realizados: são apenas válvulas de escape para essa comunidade ou existe algo para além da ludicidade? Qual o sentido e papel dos festejos realizados para esses comunitários? Como esses revelam as formas de organização dos moradores, embora exista uma série de dificuldades e descontentamentos entre eles na comunidade? Como os festejos têm contribuído para o fortalecimento dos laços entre os moradores que se sentem abandonados e desconfiados?

A partir dessas questões, encontramos boas referências na perspectiva da Psicologia Social Comunitária (PC) para respondê-las e que levaram à elaboração de pesquisa que gerou este artigo. Consideramos que essa perspectiva é adequada por estudar as comunidades e os laços construídos historicamente pelas pessoas que as habitam (Montero, 2000). A PC visa ao desenvolvimento da consciência dos comunitários como sujeitos históricos, com o objetivo de promover mudanças do contexto social onde as pessoas da comunidade estão envolvidas (Góis, 1993; Montero, 2003). Surgiu a partir de perspectivas críticas e transformadoras, tal qual a Psicologia da Libertação, que é pautada na construção de uma Psicologia capaz de auxiliar os sujeitos a conquistarem a transformação da realidade opressora, injusta e desigual, por meio da conscientização e participação social (Martín-Baró, 2011).

E o que se entende por comunidade, pela PC? Sawaia (1996) aponta que a comunidade pode ser pensada tanto como uma categoria científico-analítica (conceito abstrato para entender a relação indivíduo-sociedade) quanto como categoria orientadora de ação e reflexão (caráter sociopolítico e utópico). Assim, a autora entende que comunidade se fundamenta num Homem visto em sua totalidade, com fusão de sentimento, pensamento, tradição, ligação intencional, participação e vontade, abrangendo todas formas de relacionamento continuadas no tempo que envolvem intimidade pessoal, profundeza emocional e engajamento moral. Portanto, a comunidade não são meras relações face a face ou dadas 
num espaço geográfico, apesar destes serem sua base cotidiana de objetivação. De modo semelhante, Gomes (1999) entende que a comunidade se refere a um grupo de pessoas com grau de interação social, no qual podem repartir interesses, sentimentos, crenças e atitudes, residir em um território específico, bem como possuir um determinado nível de organização.

Portanto, o campo da PC nos abre portas para entender como e porque a comunidade Parque Riachuelo I realiza seus festejos e quais os significados que estes têm para a vida comunitária. Para tanto, é importante entender como se dá a dinâmica comunitária, o que pode ser compreendido por duas categorias da PC: redes comunitárias e fortalecimento comunitário.

Montero e Sonn (2004) pontuam que as redes comunitárias são como uma teia de relações interpessoais, na qual a passagem de informações e mediações organizadas no ambiente estabelecem o desenvolvimento, fortalecimento e alcance de objetivos dentro da comunidade. Assim, as redes comunitárias são as formas como uma comunidade se apresenta e codifica suas regras sociais, atividades e, principalmente, o fortalecimento de laços entre os comunitários. A constituição das redes comunitárias emerge dentro da organização social da comunidade, que pode ser identificada pela pluralidade dos membros, pelas convergências e divergências entre si, pelas ações coletivas, pela solidariedade e pela troca de experiências compartilhadas (Calegare, 2010). Partindo dessa noção de redes comunitárias, podemos interpretar como são construídas essas ações coletivas de organização de festejos pelos comunitários, ao passo que servem de base para explicar esse fenômeno que ocorre na comunidade.

Em concordância, Câmara (2008) aponta que a noção de fortalecimento comunitário trabalhado na perspectiva da psicossocial comunitária diz respeito ao processo em que as pessoas alcançam o despertar em si mesmas, ou seja, domínio de sua vida. O fortalecimento comunitário, por vezes chamado de empoderamento comunitário, influencia no sentimento de pertença no meio comunitário, que pode aumentar o potencial de criatividade, espontaneidade e vivacidade dos moradores para compreender os aspectos da sua realidade e direcionar esforços para a transformação social. A autora aponta que o fortalecimento comunitário se torna uma estratégia para apoiar as pessoas no processo de reflexão acerca dos problemas vividos na sociedade, de modo que aumenta a intervenção sobre a realidade e a consciência crítica.
Desse modo, o estreitamento dos laços entre os moradores são ferramentas para a efetivação de ações e metas conjuntas dos moradores. Nesse movimento, os membros da comunidade podem agir de modo consciente, direcionando para uma transformação e emancipação das condições na comunidade.

A partir desses constructos, podemos afirmar que as redes comunitárias são geradas pela maneira como são conduzidas as atividades da comunidade e que as atividades de ação-prática são afirmadoras do sentimento de pertencimento, pautadas no fortalecimento comunitário. Sendo assim, os questionamentos levantados acerca da problemática da comunidade Parque Riachuelo I podem ser compreendidos e analisados por meio das categorias de fortalecimento comunitário e redes comunitária. A partir do entendimento desses processos, podemos caminhar para o desenvolvimento comunitário, que está diretamente ligado ao desenvolvimento dos sujeitos comunitários participantes (Nepomuceno, Ximenes, Cidade, Mendonça, \& Soares, 2008).

Feitas essas considerações e tendo em conta que este texto é resultado de pesquisa de iniciação científica realizada no Parque Riachuelo I, temos por objetivo neste artigo apresentar o levantamento de quais festejos já aconteceram na comunidade e seu significado para os moradores. E a partir disso, examinar como estes foram configurados a partir das redes comunitárias e influenciaram o fortalecimento comunitário, observando que o recurso festivo pode ser um viés transformador da realidade na comunidade.

\section{Metodologia}

A pesquisa foi qualitativa de cunho exploratório-descritivo, que se caracteriza por buscar apresentar um novo olhar sobre uma determinada problemática estudada. É muito utilizada na área social, pois une ao mesmo tempo os objetivos buscados pela pesquisa exploratória, tal qual o desenvolvimento, a elucidação e transformação de ideias e/ou conceitos, bem como alcançar os objetivos da pesquisa descritiva, onde procura-se descrever características da população ou fenômeno pesquisado (Gil, 2008). No caso específico da investigação, esta técnica permitiu o desenvolvimento da pesquisa exploratória com a inserção na comunidade, bem como alcançou os objetivos de descrever os significados dos festejos para os moradores.

Nossa inserção na comunidade aconteceu por meio de conversas informais com moradores que já participaram de outras pesquisas e projetos de exten- 
são que realizamos previamente na mesma. Essas pessoas indicaram outros moradores que poderiam contribuir com a pesquisa, adotando como critério terem sido protagonistas de alguns festejos para a comunidade. Para tanto, a observação participante com registro em diário de campo fez parte do trabalho de campo, para a aproximação do pesquisador em seu local estudado e com os entrevistados (Minayo, 2013).

Depois do contato inicial com os indicados, estes foram esclarecidos quanto aos objetivos da pesquisa, aprovado pelo Comitê de Ética em Pesquisa ( $\mathrm{n}^{\mathrm{o}}$ 1.082.429/2015). Com base nas explicações e esclarecimentos prévios, os moradores assinaram um Termo de Consentimento Livre e Esclarecido, no qual formalizaram a participação na pesquisa.

Além da observação participante, elaboramos um roteiro de entrevista semiestruturada composto por 15 perguntas abertas e fechadas. $\mathrm{O}$ enfoque das perguntas se deu sobre quais eram as lembranças dos moradores a respeito de festejos ocorridos na comunidade, quando ocorreram, como foi, quem participou, quem organizou, quais as dificuldades, como se sentiram, quais os significados e qual a importância destes festejos na comunidade. A pesquisa contou com a participação de seis moradores na faixa de idade entre 16 a 65 anos, que tiveram participação ativa na organização da maioria dos festejos realizados na comunidade Parque Riachuelo I. A entrevista foi realizada com cada um dos participantes em um local reservado de sua residência, sendo feita gravação em áudio e, posteriormente, a transcrição literal para a análise dos dados.

Os dados obtidos nas entrevistas foram sistematizados e analisados de acordo com o método de análise de conteúdo (Bardin, 1995), que tem por finalidade ser um conjunto de técnicas de análise de comunicação que visa obter, através de procedimentos sistemáticos e objetivos, uma descrição do objeto estudado. Para tanto, seguiram-se as seguintes etapas: a) pré-análise, com a leitura flutuante e primeiras hipóteses e categorias; b) exploração do material, com as codificações, enumerações e regras que definem as categorias; c) tratamento dos resultados e interpretação, por meio da categorização com exemplos de trechos das entrevistas, com inferências alcançadas.

A partir dos dados obtidos e analisados, encontramos as seguintes categorias: festejos lembrados e suas formas de organização; dificuldades para organização dos festejos; importância da realização dos festejos; e o significado dos festejos para os comunitários. Os entrevistados foram identificados por nome fictício ao se utilizar trechos de seus depoimentos para exemplificar as categorias de análise dos resultados.

\section{Resultados e discussão}

\section{Festejos lembrados e suas formas de organização}

Os entrevistados expressaram a lembrança de oito festejos na comunidade: arraial da comunidade, festa do dia das crianças, festa do dia das mães, festa da igreja, festa do aniversário da comunidade, festa de páscoa, festa do dia dos pais e festa de natal. Os festejos mais lembrados e descritos amplamente foram os primeiros três, o que nos levou a compreender que as festas mais lembradas possuem uma característica em específico: oferecem algo atrativo ao morador, isto é, brindes distribuídos aos participantes. Dessa forma, percebemos que ao oferecer algo atrativo, o festejo torna-se importante e memorável. Segundo o depoimento dos moradores entrevistados, os festejos tornam-se bons a partir de arrecadações, de boa alimentação, brindes, música, dança e outras atividades realizadas e oferecidas pelo momento de celebração, como verbaliza a entrevistada:

Participei, eu fui na festa e teve dança, teve brincadeira. A festa foi boa, teve várias danças. Eles mesmo fizeram as danças, do boi, fizeram sinhazinha e coisas típicas da festa junina. A gente promoveu e a gente arrecadou brinquedos, ai a gente doou pras crianças né, os brinquedos e roupas (Luna).

Segundo Bosi (1993), “o conjunto das lembranças é também uma construção social do grupo em que a pessoa vive e onde coexistem elementos da escolha e rejeição em relação ao que será lembrado" (p. 54). A festa é uma produção de memória, de identidade no tempo e no espaço social (Guarinello, 2001). Neste sentido, destacamos que as festas mais lembradas foram escolhidas por meio da construção social sobre o que um festejo necessita para ser lembrado. Ou seja, para os moradores desta comunidade, os festejos mais lembrados são os de grande sucesso que oferecem algo ao morador, tornando-se bem quistos.

Tais fatos revelam certas características dessa comunidade e de como os moradores se organizam 
para que cada festejo seja atrativo. Os festejos têm um papel essencial para os moradores, onde refletem o modo como o grupo social pensa e percebe o local, servindo, ainda, para solidificar os laços sociais e a valorização das experiências nele (Bezerra, 2008). O festejo é uma ação coletiva que implica a concentração de afetos e emoções na reunião de seus participantes (Guarinello, 2001). Sendo assim, os festejos marcantes possibilitaram um espaço para celebrar, unir, simbolizar os laços comunitários, bem como perpetuar o momento na memória social.

Desse modo, concordando com Montero e Sonn (2004), podemos entender que o ato de organizar festejos faz com que as teias de relações interpessoais, que configuram as redes comunitárias, sejam mobilizadas. Assim, tal ato faz despertar afetos e emergir convergências e divergências entre os envolvidos - o que indicam a pluralidade existente das pessoas numa comunidade - mas sem que se perca de vista o alcance do objetivo comum. Isso tudo fica registrado na memória de quem viveu esses momentos, não apenas como algo do passado, mas como marca da rede comunitária.

Assim sendo, a organização dos festejos comunitários no Parque Riachuelo I revela que estes são utilizados para selar laços sociais, ou seja, fortalecer as redes comunitárias e mobilizar a comunidade. De acordo com a entrevistada Ana, o festejo promove o reencontro de moradores que não convivem diariamente, possibilitando uma reunião:

A festa das mães também, foi muito boa, a gente pedia e não saia ninguém sem algo da festa. Todas essas festas foram boas, pra nós, pra comunidade, pra se reunirem né. Às vezes a gente não se vê e ai vem se ver na festa (Ana).

Destacamos que os festejos mais lembrados e suas características marcam o modo como os moradores visualizam suas condições na comunidade. Como relatado na introdução deste texto, a comunidade Parque Riachuelo I possui problemas que vão desde infraestrutura à falta de opções de lazer. Os moradores não possuem nenhum espaço de lazer em toda a comunidade e quando acontecem eventos sociais, estes são promovidos por outras instituições, por exemplo pela Igreja Católica da comunidade. Existem locais, como balneários, porém não estão à disposição e à serviço da comunidade, pois são alugados para eventos particulares (Calegare et al., 2015). Logo, os festejos tornam-se uma ferramenta estratégica para que haja um encontro comemorativo e de lazer para esses moradores, que não possuem um espaço físico para isso. As manifestações comunitárias instigam encontro e diálogo cheio de significados, de forma que cada morador tem a possibilidade de exercer uma função importante na união, mobilização e representação de sua comunidade.

Para a realização desses encontros festivos, os entrevistados apontaram os principais protagonistas da organização. Foram identificados como idealizadores dos festejos aqueles que contribuíam com ideias e ajudavam na mobilização de outros moradores, assim como os que cediam os espaços físicos (suas varandas e quintais) para a realização dos eventos sociais. Nesse contexto, os idealizadores e organizadores dos festejos passam a ser apontados como pessoas de liderança, proativas e solidárias na comunidade, onde assumem o papel de agentes sociais capazes de promover uma diversidade de diálogos e resoluções acerca das problemáticas em seus espaços. Seguindo apontamentos de Montero (2003), entendemos que tais pessoas são reconhecidas por sua liderança comunitária de caráter transformador, e não autoritário. A autora aponta que esse tipo de liderança envolve características lembradas pelos nossos entrevistados: serem pessoas ativas, participativas, que agem com amor e dedicação, esperança e otimismo, e que assumem suas tarefas como serviços em prol do coletivo e como obra de suas vidas.

Cabe pontuar, então, que estes líderes comunitários organizadores dos festejos são importantes para o fortalecimento das redes comunitárias, visto que se mobilizam e fazem acontecer as festividades para o lazer da comunidade e, principalmente, permitem a promoção de um espaço de pluralidade para o surgimento de novos agentes. Traduzindo em termos teóricos, é na complexidade das relações de variados membros da comunidade, instituições, associações e outros, que emergem as figuras de liderança que mobilizam as redes comunitárias em prol do enfrentamento dos problemas na comunidade - o que se torna importante para o fortalecimento do sentimento comunitário e desenvolvimento social (Montero, 2004). Logo, o surgimento de lideranças comunitárias é essencial para que se alcancem os objetivos comunitários. Esse ativismo dos líderes comunitários é lembrado pela entrevistada Bia, que informou que as principais atividades de organização dos festejos incluíam pedir ajuda e doação aos moradores: 
Geralmente, faz uma relação de que vai fazer e convida os moradores. Ai cada qual doa alguma coisa: bolo, mingau e os coordenadores pegam aquelas coisas pra vender e eles ficam coordenando, botando dança, inventando bingo e é assim que procede a festa (Bia).

A partir desse relato, percebemos que o protagonismo desses moradores instiga aos demais à organização em redes de relações. A existência dos agentes sociais nos remete a uma íntima relação com as questões de fortalecimento de identidade comunitária, haja vista que a participação e o engajamento que os moradores mostraram são peças fundamentais para uma mobilização de todos acerca de outras demandas enfrentadas no cotidiano. Moura Junior, Cardoso, Rodrigues, Vasconcelos e Ximenes (2013) afirmam que o festejo traz a possibilidade de um aprofundamento de consciência e de relações afetivas, de forma que desvela a realidade e repercute um movimento de fortalecimento e libertação para essa população.

Ainda sobre a organização dos festejos, percebemos outra característica importante a ser destacada: a influência familiar. As entrevistadas Maria, Luna e Bia possuem grau de parentesco, bem como os entrevistados Carlos e João. Todos são protagonistas da promoção dos festejos. No contexto do desenvolvimento humano, a família tem um papel fundamental e uma forte influência no comportamento dos sujeitos e suas relações sociais (Dessen, \& Polonia, 2007). Assim, percebemos que, para essa comunidade, o seio familiar possui um papel importante para a revelação de atores sociais capazes de transformar seu meio social, sendo necessário aprofundamento em futuras pesquisas para interpretar de forma ampla tal peculiaridade.

\section{Dificuldades para a organização dos festejos}

Os entrevistados mencionaram diferentes dificuldades quanto à organização dos festejos, sendo mescladas as respostas. Alguns, como o entrevistado Elio, acreditou não ter nenhuma dificuldade na organização. Contudo, o morador João especificou algumas dificuldades, como "uma vez que faltou luz no meio da festa. E o pessoal do som ficou tudo ai, mas mesmo assim continuamos a festa" (João). Maria menciona que a dificuldade está relacionada a conseguir apoio com as redes para patrocínio das festas. Já a entrevistada Bia aponta as dificuldades em convi- dar a todos da comunidade. A entrevistada Ana reflete sobre falta de participação dos novos moradores nos festejos como uma grande dificuldade para realização e afirma que:

Uns moradores só põe banca e não sabe o que nós já passamos aqui na comunidade pra conseguir as coisas... Quando a gente chama pra festa às vezes eles vão, participam, mas uns outros não, não querem nem saber de nada.

Verificamos que as complicações e dificuldades expostas sobre a organização dos festejos são reflexos das outras problemáticas da comunidade, relacionadas à mobilização e ao engajamento dos moradores para questões políticas e sociais. A ausência da participação de novos moradores, apontada previamente na introdução deste artigo, é proveniente de diversos fatores, desde a divergência nos interesses políticos, até aspectos de ordem econômica, social e simbólica entre os moradores. Como explica Bordenave (2011), isso não é um fenômeno exclusivo da comunidade, pois a própria sociedade brasileira não possui uma organização social que propicie às pessoas fazer parte - a própria origem da palavra participação. Ainda segundo o autor, a estratificação de classes no Brasil historicamente tem dificultado a participação em maior grau das bases populares nas tomadas de decisões. E tal estratificação também é verificada na comunidade.

A maneira como as pessoas se situam e se posicionam no seu cotidiano afeta na construção de suas relações sociais e de suas histórias de vida, o que nos remete para a ideia de que a intervenção na realidade de uma comunidade deve ser permeada pelo processo de conscientização comunitária acerca de sua própria história e do que é possível ser alcançado com a emancipação. Freire (1979) dialoga em sua teoria que a conscientização implica numa ação reflexiva pela qual nos deparamos com a realidade de modo crítico, em contraposição a uma realidade meramente automática, rasa e sem qualquer reflexão sobre ela. Assim, a conscientização acontece à medida que a pessoa se torna sujeito consciente e das ações de sua vida. Dessa maneira, intervir dentro da comunidade frente aos problemas apresentados deve partir da promoção da construção de diálogos que possibilitem a reflexão para uma tomada de consciência e, então, encontrar estratégias de enfrentamento da problemática em que se encontra a pessoa. 
Nesse contexto, os sentimentos destacados pelos entrevistados revelam o enfraquecimento dos laços de solidariedade comunitária. Desse modo, os espaços promovidos de atuação e protagonismo dos moradores tornam-se cada vez mais importantes para a transformação da realidade. O festejo funciona, então, como um espaço para que ocorra a mobilização entre os moradores. Assim, apesar das dificuldades apresentadas pelos entrevistados nas organizações desses festejos, destacamos o relato da entrevistada Maria que revela a crescente participação nos mesmos nos festejos:

Dá pra ver a diferença entre uma festa e outra... E muito. A diferença é neles presentes. Então, essa é diferença que a gente nota. Porque assim, tem mais moradores que não tinha antes. Já tem mais moradores chegando e a cada festa eles participam mais quando tem (Maria).

Essa maior participação também foi mencionada pela entrevistada Bia quando questionada a respeito do sentimento de estar participando e ajudando nas barracas dos festejos:

Nesse [festejo de arraial] deu muita gente e todo mundo ficou: "meu Deus, como assim? Muita gente"; e cada vez tem mais gente da comunidade vindo pras festas e conhecendo o que estamos fazendo e querendo fazer também alguma coisa pra ajudar as próximas festas que a gente tá planejando (Bia).

Percebemos, portanto, que os festejos têm possibilitado a união e evocação do sentido de participação comunitária, visto que chamam atenção para uma participação não somente durante as comemorações, como também em futuras organizações dos festejos. Entendemos que esse é um processo demorado, tendo em vista o contexto histórico da comunidade Parque Riachuelo I. Porém, aos poucos, cada vez mais os moradores se sensibilizam para participar e se engajar em alguma tarefa coletiva, de modo que os festejos se mostram como possíveis recursos estratégicos para o fortalecimento dos laços nessa comunidade e por consequência o estreitamento de suas redes.

\section{Importância da realização dos festejos}

Nesse ponto da discussão dos resultados, observamos que a importância dos festejos se relaciona a aspectos referentes aos sentimentos de pertença, união e criticidade. As entrevistas revelaram momentos nos quais os moradores foram emotivos e explanaram que os festejos são importantes para a união dos moradores, para o lazer e o divertimento, assim como para a visibilidade dos que estão em condições de miserabilidade na comunidade.

A moradora Maria enfatizou que os festejos como os realizados nas datas comemorativas do dia das mães abrangem não tão somente o prazer de celebrar, mas também permitem certa notoriedade para as mães da comunidade, que se sentem abandonadas por um contexto opressor. Ao serem homenageadas no festejo, sentem-se lembradas e importantes para o seio comunitário. Esse sentimento de abandono está marcado em diversas populações, levando as pessoas a construir os mecanismos de sobrevivência, ignorando outros questionamentos e se contentando com o aqui e o agora (Grandesso, \& Barreto, 2010). Logo, os festejos realizados têm oferecido momentos de descontração e de visibilidade para os moradores dessa comunidade, ao passo que deixam de ser apenas um lazer e passam a ocupar uma forma de enfrentamento para desconstruir o sentimento de abandono. Acompanhando o entendimento teórico de Montero (2003), esses festejos têm favorecido processos psicossociais que potencializam as redes comunitárias, por fortalecer a inclusão social, o reforço de identidades sociais, o intercâmbio de vivências comuns e a mobilização de afetos.

Desse modo, percebemos que os festejos são mecanismos para o processo de fortalecimento comunitário. Isso porque, de acordo com Grandesso e Barreto (2010), "tal qual a teia de aranha, a cultura é para o indivíduo o que a teia é para a aranha: ela agrega, une, alimenta e fortalece os vínculos que conferem a pertença" (p. 22). Nesse aspecto, o morador Elio destaca que a festa possui a "importância de trabalhar em equipe, com o objetivo maior de união das pessoas, unir formas de pensar para um só objetivo". Também destacamos a fala da moradora Ana que acredita "que a festa é muito útil pra quem não sai, assim pra fora, porque tem muita violência né. E aqui todo mundo se conhece, fica mais fácil”, onde revela os laços de confiança e segurança que as redes comunitárias podem propiciar. Nesse sentido de conhecer-se uns aos outros, outra moradora pontuou que:

A importância das festas foi de conhecer os novos moradores né. Porque ninguém se conhecia mais direito. Porque agora tem muita gente nova no 
bairro e nesse dia deu pra conhecer bastante pessoas. E foi assim bem legal pra unir mais a comunidade. E quanto mais tem essas festas, une mais assim. Acho que pra animar o pessoal, porque aqui é muito parado, o pessoal não se envolve bem. Acho bem legal assim fazer as festas por isso. Sobre as crianças é importante pra eles saberem que eles são lembrados pela comunidade e que a gente tá sempre ali querendo o bem deles, ajudar no que for preciso (Bia).

Segundo Bueno (2008) o festejo abrange cidadania e desperta consciência de comunidade, trazendo uma importância cultural, como modelo de ação. Desperta o sentimento de solidariedade nos moradores e abre espaços para o reconhecimento entre os mesmos. Portanto, os festejos realizados nessa comunidade não representam apenas um momento de ludicidade e descontração. Eles possibilitam afirmações e atividades comunitárias capazes de integrar moradores isolados. Assim, os festejos funcionam como importantes potencializadores de processos psicossociais que fortalecem as redes comunitárias, favorecendo a união e os laços grupais que modelam as identidades comunitárias (Montero, 2003). Nesse sentido, o sentimento de pertença comunitária é essencial, pois sem ele a comunidade se desintegra e gera vários resultados negativos, como anomia e isolamento (Lima, \& Bonfim, 2009). Além disso, o festejo não impõe uma desconstrução da ordem social, mas propõe a sua essência transformadora (Felipe, 2008).

Essa essência transformadora esteve presente durante todas as entrevistas realizadas, onde o festejo mostrou ser uma estratégia para a reunião, engajamento e visibilidade desses moradores. Esses processos psicossociais possibilitaram o fortalecimento do sentimento comunitário, o que reflete no estreitamento das redes comunitárias e da autopercepção dos moradores como um coletivo.

\section{Significado dos festejos para os comunitários}

Os entrevistados expressaram que os festejos possuem significados dinâmicos. Versam sobre a união comunitária, o engajamento e a motivação dos moradores, o lazer como forma de divertimento e a questões relacionadas às lutas políticas. A respeito da união comunitária, verificamos que os entrevistados possuíam um desejo em comum: unir a comunidade e celebrar. Ou seja, utilizar-se do recurso festivo para a união e encontro desses moradores:

Com essas programações a gente chama a comunidade, se comunica com a comunidade e se une muito mais com a comunidade. Então, na minha visão, se a gente une mais brincadeira, sem ser dia das mães, dia das criança, mas fazer um torneio, fazer outras coisas. Porque isso chama mais a comunidade um pra perto do outro (Maria).

Como pontuamos previamente, um dos fatores de desunião dos moradores está enraizada pelo histórico da comunidade: alguns moradores estão satisfeitos com as características rurais, enquanto outros sentem-se prejudicados e reivindicam um local plenamente urbanizado. Por outro lado, o maior desejo de muitos moradores é reunir todos em prol do local em que vivem, precisam zelar e resolver problemáticas. Dessa forma, notamos que os significados dos festejos sobressaem à ludicidade: esses festejos são utilizados para afirmar a coesão dos habitantes e ainda para construir e ressignificar a identidade dos comunitários historicamente oprimidos (Bezerra, 2008).

Há ausência de espaços de lazer para as crianças e moradores, além de estruturas físicas como escolas e outras instituições necessárias para um ambiente digno de convivência, que são motivos de insatisfação para muitos comunitários. Assim, os festejos traduzem as experiências e imagens da sociedade (Bezerra, 2008), de modo que Maria apontou os sentimentos que surgem e de experiências que somente foram conquistadas por meio do festejo transformador na vida destes moradores, como no relato abaixo:

O que o festejo significou foi assim: eles tão vendo a necessidade de a gente fazer alguma coisa pra essas crianças né. Porque as nossas crianças aqui são muito abandonadas, nós temos uma escola de pré, não é nem uma escola, é uma creche e os nosso, nossas crianças saem daqui pra estudar em outros colégio, nos colégio não tem uma quadra, não tem nada que eles possam brincar e nesse dia eles vieram pra cá e brincaram né. Brincaram de bola, brincaram de corrida com colher na boca com ovo, então eles se sentiram feliz (Maria).

De acordo com Rebouças Júnior e Ximenes (2010), a comunidade permite a construção de rela- 
ções entre os moradores, onde perpassam sentimentos de pertença, vínculos afetivos e problematizações sobre a realidade. É neste aspecto que quando questionados sobre o significado dos festejos, os moradores refletem e exploram sobre os dilemas e as conquistas comunitárias, que configuram as redes comunitárias e que são motivo de mobilizações.

Assim, a moradora Bia destacou que "foi muito bom tá ali vendo tudo, não tem nem palavras. Ai, foi assim uma alegria pra mim né. Tá lá, ajudando. Vê todo mundo ajudando, um ajudando o outro". Traduzimos que a organização dos festejos e o momento de estar em conjunto gerou um sentimento agradável nestes moradores, que se revelou como um alicerce para a elaboração dos vínculos afetivos e da mobilização comunitária. Portanto, mais indícios que nos levam a afirmar que os festejos nessa comunidade funcionam com uma estratégia psicossocial de potencialização das redes comunitárias em prol do fortalecimento comunitário e da resolução de problemas comunitários.

Igualmente, a mobilização para a organização dos festejos não aconteceria se não houvesse o engajamento comunitário. Conforme o morador João, o significado dos festejos dá-se porque "é bom tá nas festas, tá todo mundo junto né. A gente se vê e se conversa, festeja, tem dança, comida boa, som alto". Ou seja, o momento de estar junto transforma a comunidade, de forma que potencializa os sentimentos de pertença, em detrimento aos pensamentos pessimistas e de desesperança a respeito das problemáticas do contexto em que enfrentam no cotidiano.

O sentimento de desesperança e desmotivação acerca da situação dos terrenos (irregulares por grilagem) e da deficiente infraestrutura urbana são recorrentes nos discursos dos moradores, o que revela também a desconfiança quanto aos representantes da associação da comunidade. Isso gera uma desunião dos comunitários para uma mobilização política, participação e engajamento às outras demandas da comunidade, como por exemplo as reivindicações por melhores condições de saneamento básico. Dessa forma, o clima de desconfiança quebra os vínculos de solidariedade e gera conflitos e intrigas (Grandesso, \& Barreto, 2010).

Contudo, o que verificamos foi que durante e após os acontecimentos dos festejos, os vínculos de solidariedade foram fortalecidos e as ações conjuntas em prol dos festejos permitiram que outras reu- niões sejam realizadas. Maria expressou que "quando termina um festejo nós já pensamos em organizar o outro e também já estamos reunindo o pessoal pra fazer uma chapa pra próxima eleição da associação aqui da comunidade". Desse modo, vimos que o espaço promovido pelo festejo possibilitou a idealização de outras questões mais políticas da comunidade, como a construção de chapas concorrentes à AMAR.

As lutas políticas foram também relatadas como aspectos significantes proveniente do momento dos festejos. O morador Elio relatou que o festejo "significou contribuir. Buscar dar minha contribuição para a união das pessoas e melhorias do nosso bairro". Segundo outra entrevistada:

É assim que eu contribuo pra nossa comunidade, é até o caso da urbanização, fato que a gente já lutou muito com a dona Maria atrás, mas só pega não, não e não. Aquela rua lá de baixo que foi asfaltada foi nós, foi por causa da nossa insistência de nós duas. No pé o tempo todo. Era muito feio pra banda ali do rumo do seu Chiquinho era só lama. E ai a festa vem pra ser muito boa, pra comemorar, pra conversar sobre essas coisas (Ana).

Assim, percebemos que os festejos possuem um significado ainda velado e a participação dos moradores na organização dos festejos são formas de contribuir para o desenvolvimento da comunidade. Calegare et al. (2015) afirmam que a comunidade Parque Riachuelo I encontra-se em condições precárias: falta escola, área de lazer, linha de ônibus interna, segurança e a situação de muitos moradores é de vulnerabilidade social. Por isso, essas lutas políticas lembradas nas entrevistas são fundamentos do processo de conscientização, mobilizações e ações coletivas, o que conduz para que essa comunidade transforme seu contexto atual.

Conforme Moura Junior et al. (2013), a realidade brasileira (e latino-americana) situa o povo em posições de inferioridade e conformismo que enfraquecem o potencial transformador de cada sujeito. Porém, o festejo para essa comunidade se destaca como forma de arte e seus significados são aliados fundamentais para a conscientização dos moradores. A arte é forjada na dinâmica popular e é de extrema importância para surgir a educação e suas formas de conscientização, de modo que expressa livremente o ser como potência de ideias e ideais (Cruz, Freitas, \& Amoretti, 2010). 
Em suma, ao resgatarmos os significados dos festejos para os comunitários, verificamos que estamos diante de uma mobilização diferente, apesar de tímida. Entretanto, ressaltamos que é um tipo de mobilização bastante promissora e que permite gerar conscientização dos moradores de suas condições de opressão, abandono e desesperança.

\section{Considerações finais}

Este texto buscou resgatar quais festejos já ocorreram na comunidade Parque Riachuelo I, a fim de entender como influenciaram no fortalecimento dos laços entre os moradores da comunidade. A partir dos relatos dos entrevistados, notamos que os festejos têm certo impacto nos processos de participação e mobilização, podendo ser entendidos não apenas como eventos lúdicos, mas como movimentos de transformação da comunidade. Assim, foi possível verificar que os festejos funcionaram como uma estratégia psicossocial que potencializa as redes comunitárias, fazendo com que os moradores se encontrem, conversem, brinquem, comam, se unam e, ao fazer tudo isso, tomem consciência de sua condição e procurem lutar por uma vida melhor.

Verificamos também que os festejos mais lembrados foram marcados por ações conjuntas e solidárias entre os moradores organizadores dos festejos e, principalmente, marcados pelo oferecimento de algo atrativo (brindes, presentes). Isso porque, em virtude do contexto histórico da comunidade de isolamento entre seus moradores, os festejos precisavam chamar a atenção para que os comunitários pudessem aderir ao momento de lazer proposto. E tal chamado vinha por meio desses presentes. Fica então uma questão a ser investigada e debatida futuramente: qual o significado desse bem material, para que o mesmo fosse lembrado como algo marcante dos principais festejos?

Por outro lado, as ações conjuntas dos moradores organizadores foram desde contribuir com dinheiro, ornamentação, comida, presentes, até convidar de porta em porta os moradores. Nesse aspecto, os organizadores compartilharam objetivos em comum, expectativas, enfrentando juntos as dificuldades, como por exemplo os problemas técnicos e a falta de patrocínio, da mesma forma em que encontraram soluções de enfrentamento juntos. Isso fez com que houvesse também aderência de outros moradores até então alheios às atividades da comunidade, propiciando a participação de novas pessoas nas atividades comunitárias e na organização dos outros festejos. Isso nos remete à ideia de que os festejos não são mera atividade lúdica, mas são uma estratégia de atividade comunitária e de colaboração mútua que fortalece as redes comunitárias. E ao se envolverem em sua organização, ou meramente participando dos festejos, os moradores encontram uma oportunidade de refletir e, assim, conscientizar-se das condições da vida na comunidade Parque Riachuelo I.

Os comunitários relataram de diversas maneiras suas percepções a respeito da desunião e da desesperança em que muitos se encontram na comunidade, uma vez que predomina um clima de desconfiança acerca dos representantes da associação dos moradores, assim como um sentimento de abandono pelo poder público. Em tais condições, vimos a importância dos festejos, sobre os quais os entrevistados referiram-se como um recurso para uni-los em um evento social e de lazer, mas que resultava também como um de espaço para configurar lutas comunitárias.

Assim sendo, os festejos foram importantes meios para a união das pessoas que perderam seus laços comunitários ou que tinham tais laços enfraquecidos. Pelo relato dos entrevistados, vimos que os festejos funcionaram como importante meio de fortalecimento dos laços de pertencimento e solidariedade entre os moradores. Em suma, um movimento festivo que possibilitou o contato primário, a conversa, os questionamentos e o delineamento de estratégias de enfrentamento das dificuldades comunitárias.

Portanto, chegamos à conclusão de que o festejo é a reunião. É um momento em que esses moradores se divertem, conhecem novos moradores e discutem sobre assuntos comunitários que incluem lutas políticas. O festejo possibilita um espaço onde há trocas culturais, discussões ideológicas e onde se tem abertura para o surgimento de novos agentes sociais, capazes de mobilizar a comunidade para outras problemáticas. Assim, os festejos são importantes para agregar, unir e potencializar as redes comunitárias, especificamente na comunidade Parque Riachuelo I, de modo que se torna visível o impacto na vida dos moradores em seus relatos, como por exemplo: as questões referentes ao sentimento de pertença, de valorização e empoderamento, quando mães e crianças recebem brindes e são lembradas e homenageadas. Dessa forma, pudemos perceber que os comunitários se identificam e se sentem comprometidos socialmente com os eventos, facilitando o engajamento e a presença dos mesmos nos festejos. 
Por fim, chamamos atenção para um resultado relacionado ao engajamento comunitário e as relações de parentesco: os laços familiares. Nos discursos dos moradores entrevistados, vimos que grande parte dos organizadores e participantes ativos dos festejos tem uma relação de parentesco. Essa característica nos motivou ao questionamento e à busca de referências em PC que pudessem contemplar os aspectos da influência familiar nas questões de engajamento, mobilização e participação em atividades comunitárias, especialmente as de cunho político. Constatamos que esse é um campo temático que carece de produções e que pode ser alvo de futuras pesquisas e teorizações para enriquecer a perspectiva e abrir espaço para a discussão e interpretações desses fenômenos relacionados à comunidade.

Igualmente, levantamos questionamentos sobre a escassa produção científica acerca dos festejos à luz da PC. Consideramos que os resultados dessa pes- quisa trazem novas ferramentas à PC, por fornecer subsídios que reafirmam os festejos como um instrumento para auxiliar no processo de conscientização e de transformação da realidade opressora em que se encontram os moradores.

Concluímos, então, que os festejos realizados na comunidade Parque Riachuelo I são mediadores no processo de conscientização e autonomia, estando para além do momento de ludicidade: são possíveis estratégias de fortalecimento comunitário, por terem sido revelados ao longo dos resultados dessa pesquisa como práticas que unem e agregam os moradores da comunidade. Assim, funcionam como estratégias psicossociais que potencializam as redes comunitárias e as identidades locais, gerando sentimento de pertença e, por consequência, influenciando diretamente na participação política dos comunitários frente às problemáticas de sua comunidade.

\section{Referências}

Bardin, L. (1995). Análise de conteúdo. Lisboa: Edições 70.

Bezerra, A. C. A. (2008). Festa e cidade: Entrelaçamentos e proximidades. Espaço e Cultura, 23, 7-18.

Bordenave, J. E. D. (2011). O que é participação (8a ed.). São Paulo, SP: Brasiliense.

Bosi, E. (1993). A pesquisa em memória social. Psicologia USP, 4(1/2), 277-284.

Bueno, M. S. (2008). Lazer, festa e festejar. CULTUR, 2(2), 47-59.

Calegare, M. G. A. (2010). Contribuições da Psicologia Social ao estudo de uma comunidade ribeirinha no Alto dos Solimões: redes comunitárias e identidades coletivas (Tese de doutorado). Instituto de Psicologia, Universidade de São Paulo, São Paulo, SP, Brasil.

Calegare, M. G. A., Ribeiro, J. H. S., Costa, C. R. B. S. F., Pires, E. A., \& Souza, J. C. P. (2015). Participação e conscientização dos moradores no Parque Riachuelo (Relatório de extensão). Faculdade de Psicologia, Universidade Federal do Amazonas, Manaus, AM, Brasil.

Câmara, S. G. (2008). Compromisso, participação, poder e fortalecimento comunitário: à procura de um lugar no mundo. In M. Dimenstein (Org.), Psicologia social comunitária: aportes teóricos e metodológicos (pp. 43-58). Natal, RN: EDUFRN.

Castro, J. R. B. (2012). Concepções de festa, os sentidos do festejar e as dimensões socioeconômicas, culturais e lúdicas das festas juninas. In J. R. B. Castro (Org.), Da casa à praça pública: a espetacularização das festas juninas no espaço urbano (pp. 39-84). Salvador, BA: EDUFBA.

Cruz, L. R., Freitas, M. F. Q., \& Amoretti, J. (2010). Breve história e alguns desafios da Psicologia Social Comunitária. In J. C. Sarriera, \& E. T. Saforcada (Orgs.), Introdução à Psicologia Comunitária: bases teóricas e metodológicas (pp.76-96). Porto Alegre, RS: Sulina.

Dessen, M. A., \& Polonia, A. C. (2007). A família e a escola como contextos de desenvolvimento humano. Paidéia, 17(36), 21-32. https:// doi.org/10.1590/S0103-863X2007000100003

Felipe, J. L. A. (2008). Festa e poder político. Espaço e Cultura, (23), 43-52. https://doi.org/10.12957/espacoecultura.2008.3521

Freire, P. (1979). Conscientização: teoria e prática da libertação: Uma introdução ao pensamento de Paulo Freire. São Paulo, SP: Cortez \& Moraes. 
Gil, A. C. (2008). Métodos e técnicas de pesquisa social. São Paulo, SP: Atlas.

Góis, C. W. L. (1993). Noções de psicologia comunitária. Fortaleza, CE: Edições UFC.

Gomes, A. M. A. G. (1999). Psicologia comunitária: Uma abordagem conceitual. Psicologia Teoria e Prática, 1(2), 71-79.

Grandesso, M., \& Barreto, M. R. (2010). Terapia comunitária: Tecendo redes para a transformação social. São Paulo, SP: Casa do Psicólogo.

Guarinello, N. L. (2001). Festa, trabalho e cotidiano. In I. Jancsó, \& I. Kantor (Orgs), Festa cultura e sociabilidade na América Portuguesa (pp. 969-975). São Paulo, SP: EDUSP.

Lima, D, M. A., \& Bomfim, Z. A. C. (2009). Vinculação afetiva pessoa-ambiente: diálogos na psicologia comunitária e psicologia ambiental. Psico, 40(4), 491-497.

Lobato, S. (2014). A historiografia da migração na Amazônia do século XX: Pressupostos, teses, debate. Fronteiras no Tempo, (5), 11-26.

Martin-Baró, I. (2011). Para uma psicologia da libertação. In R. S. L. Guzzo, \& F. Lacerda Junior (Orgs.), Psicologia social para América Latina: o resgate da psicologia da libertação (pp. 181-197). Campinas, SP: Alínea.

Minayo, M. C. S. (2013). Pesquisa social: Teoria, método e criatividade. Petrópolis, RJ: Vozes.

Montero, M. (2000). Construcción, desconstrucción y crítica: Teoría y sentido de la psicología social comunitaria en América Latina. In R. H. F. Campos, \& P. A. Guareschi (Orgs.), Paradigmas em Psicologia Social: A perspectiva Latino-Americana (pp. 70-87). Petrópolis, RJ: Vozes.

Montero, M. (2003). Teoría y práctica de la psicología comunitaria: La tensión entre comunidad y sociedad. Buenos Aires: Paidós.

Montero, M. (2004). Introducción a la psicología comunitaria: Desarrollo, conceptos y procesos. Buenos Aires: Paidós.

Montero, M., \& Sonn, C. (2004). Psychology of liberation: Theory and applications. New York, NY: Springer.

Moura Junior, J. F., Cardoso, A. A. V., Rodrigues, D. C., Vasconcelos, R. M., \& Ximenes, V. M. (2013). Práxis em psicologia comunitária: Festa de São João como atividade comunitária. Revista Ciência em Extensão, 9(1), 105-123.

Nepomuceno, L. B., Ximenes, V. M., Cidade, E. C., Mendonça, F. W. O., \& Soares, C. A. (2008). Por uma psicologia comunitária como práxis de libertação. Psico. 39(4), 456-464.

Nogueira, W. (2008). Festas amazônicas: Boi-bumbá, ciranda e sairé. Manaus, AM: Valer.

Pinto, J. G. (2008). Análise introdutória do processo de ocupação urbana em Manaus e suas consequências socioambientais: O estudo de caso das comunidades São Pedro, Arthur Reis e Bariri (Dissertação de mestrado). Universidade Federal do Amazonas, Manaus, AM, Brasil.

Rebouças Júnior, F. G., \& Ximenes, V. M. (2010). Psicologia comunitária e psicologia histórico-cultural: Análise eVivência da atividade comunitária pelo método dialógico-vivencial. Pesquisas e Práticas Psicossociais, 5(2), 151-162.

Sawaia, B. B. (1996). Comunidade: a apropriação científica de um conceito tão antigo quanto a humanidade. In R. H. F. Campos (Org.), Psicologia social comunitária: Da solidariedade à autonomia (pp. 35-53). São Paulo, SP: Vozes.

\section{Kamila Bezerra de Araújo}

Bacharel em Psicologia pela Universidade Federal do Amazonas.

E-mail: kamilabdearaujo@gmail.com

\section{Marcelo Gustavo Aguilar Calegare}

Professor Adjunto da Faculdade de Psicologia da Universidade Federal do Amazonas.

E-mail:mgacalegare@ufam.edu.br 
Endereço para envio de correspondência:

Universidade Federal do Amazonas, Faculdade de Psicologia.

Av. General Rodrigo Octávio, 6200, Setor Sul, Campus Universitário, Bloco X

Coroado I. CEP: 69080-900.

Manaus - AM. Brasil.

Recebido: 19/06/2017

Aprovado: 07/05/2018

Received: 06/19/2017

Approved: 05/07/2018

Recibido: 19/06/2017

Aceptado: 07/05/2018

Como citar: Araújo, K. B., \& Calegare, M. G. A. (2018). Os festejos como estratégia de fortalecimento comunitário em comunidade de Manaus (AM). Psicologia: Ciência e Profissão, 38(3), 537-550.

https://doi.org/10.1590/1982-37030002292017

How to cite: Araújo, K. B., \& Calegare, M. G. A. (2018). The festivities as a strategy for community strengthening in a Manaus (AM) community. Psicologia: Ciência e Profissão, 38(3), 537-550.

https://doi.org/10.1590/1982-37030002292017

Cómo citar: Araújo, K. B., \& Calegare, M. G. A. (2018). Los festejos como estrategia de fortalecimiento comunitario en comunidad de Manaus (AM). Psicologia: Ciência e Profissão, 38(3), 537-550.

https://doi.org/10.1590/1982-37030002292017 